\title{
Internet of Things (IoT) Based Smart Plant Monitoring System
}

\author{
Dr.M.Vidhyalakshmi ${ }^{1} \mid$ H.Peer oli ${ }^{2} \mid$ N.Hemakumari ${ }^{2} \mid$ S.Bismillah Khan ${ }^{2} \mid$ Dr.C.Priya ${ }^{2}$ \\ ${ }^{1}$ Electronics and Communication Engineering, SRM institute of Science and Technology, Ramapuram, Tamil nadu, India. \\ ${ }^{2}$ Electronics and Communication Engineering, Mohamed Sathak Engineering college, Kilakarai, Tamil nadu, India.
}

To Cite this Article

Dr.M.Vidhyalakshmi., H.Peer oli., N.Hemakumari., S.Bismillah Khan \& Dr.C.Priya. Internet of Things (Iot) Based Smart Plant Monitoring System. International Journal for Modern Trends in Science and Technology 7, 144-146 (2021).

Article Info

Received on 18-April-2021, Revised on 11-May-2021, Accepted on 19-May-2021, Published on 22-May-2021.

\section{ABSTRACT}

In this work, we have a tendency to gift a plantation observance system supported web of Things. The system combines wireless detector network, embedded development, GPRS communication technology, net service, and automaton mobile platform. The hardware style of detector nodes, data acquisition, knowledge transmission, beside knowledge image and abnormal alarm ar mentioned well. Long-term experiment of the system shows that the theme is possible and reliable.

Keywords- Internet of Things; surroundings monitoring; wireless detector network; net service

\section{INTRODUCTION}

With the over-abuse of common assets, human being is confronted with progressively climate emergency, for example, energy lack, the a dangerous atmospheric devastation, deforestation, desertification and other ecological issues, so timberland ecological security turns out to be increasingly significant. Environmentalists regularly think the thickness of trees is vital for woodland development, however absence of supporting information inconveniences them. To consider the exact impacts of thickness on estate, scientists need long haul observing on an assortment of biological pointers. Notwithstanding, it is hard to gather naturally and dependably ecological observing information with conventional observing framework.

Web of things gives the specialized establishment to achieving thistask. Web of things is an organization that interfaces anything to the Internet can trade data through Radio Recurrence Identification (RFID), sensor organizations, Global Situating System (GPS) and other data detecting gadgets, as indicated by the concurred conventions, to accomplish insightful recognize, find, track, screen and manage[1][2]. Web of Things has availability for whenever, anyplace, anybody and anything. Along these lines, focusing on the qualities of ranch, we build up an estate observing framework which dependent on Internet

\section{LITREATURE SURVEY}

We have studied many previous works done in this field by different researchers. Use of technology in the field of agriculture plays important role in increasing the production as well as in reducing the man power efforts. Research for improving agricultural production by utilizing different controllers like PIC microcontroller,8051 controller, ARM 7 etc or also monitoring done by different communication technology like Zigbee, Wireless sensor network(WSN), even using GSM. Greenhouse monitoring and control system based on wireless Sensor Network by Marwa Mekki et al.In this paper a WSN was implemented by deployed wireless 
sensor nodes in a greenhouse with temperature, humidity, moisture light, and $\mathrm{CO} 2$ sensors.

To control the environmental factors, the used microcontroller programmed to control the parameters according to preset values, or manually through a user interface panel. A ZigBee based energy efficient environmental monitoring alerting and controlling system by K. Lokesh Krishna et al, the paper based on paper a novel ZigBee based energy efficient environmental monitoring, alerting and controlling system for agriculture is designed and implemented. This system utilizes an ARM7 processor, various sensors and ZigBee communication module. Sensors gather various physical data from the field in real time and transmit it to the processor and to the end user via ZigBee communication. Then necessary actions are initiated to perform action on behalf of people to reduce or eliminate the need of human labor.

Embedded based Green House Monitoring system using PIC microcontroller by S. Arul Jai Singh at al, the paper deals with a simple, easy to install, microcontroller-based circuit to monitor and record the value of temperature, humidity, soil moisture and sunlight of the natural environment that are continuously modified and controlled in order optimize them to achieve maximum plant growth and yield. The controller communicates with the various sensor modules in real-time in order to control the light, aeration and drainage process efficiently inside a greenhouse by actuating a cooler, fogger, dripper and lights respectively according to the necessary condition of the crops

\section{DESIGN OF PROPOSED SYSTEM}

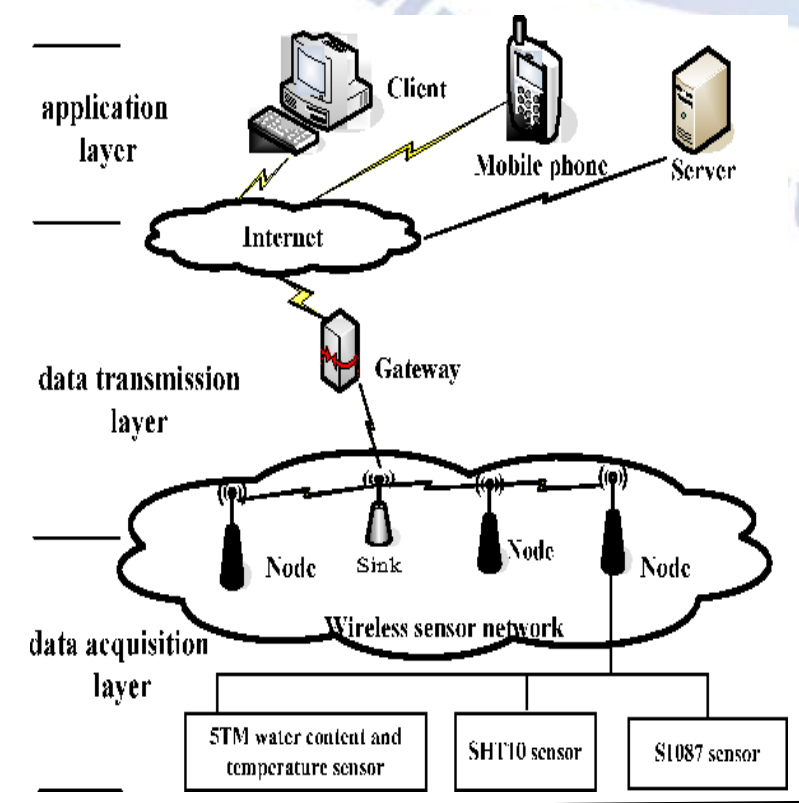

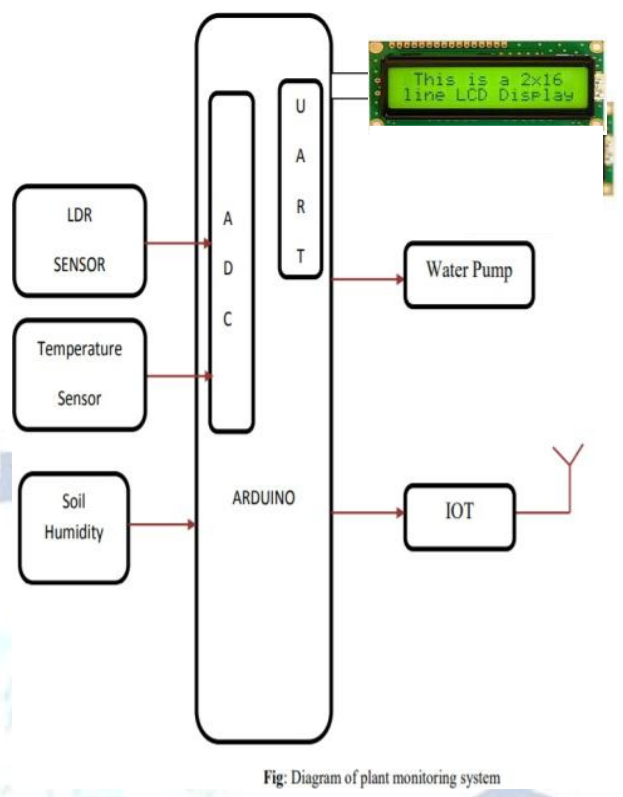

\section{IMPLEMENTATION \& WORK}

Arduino is an open source computer hardware and software company, project, and user community that preassembled form, or as do-it-yourself (DIY) kits.Arduino board designs use a variety of microprocessors and controllers. The boards are equipped with sets of digital and analog input/output (I/O) pins that may be interfaced to various expansion boards (shields) and other circuits. The boards feature serial communications interfaces, including Universal Serial Bus (USB) on some models, which are also used for loading programs from personal computers.

The microcontrollers are typically programmed using a dialect of features from the programming languages $\mathrm{C}$ and $\mathrm{C}++$. In addition to using traditional compiler tool chains, the Arduino project provides an integrated development environment (IDE) based on the Processing language project. In an industry during certain hazards is will be very difficult to monitor the parameter through wires and analog devices such as transducers. To overcome this problem we use wireless device to monitor the parameters so that we can take certain steps even in worst case. Few years back the use of wireless device was very less, but due the rapid development is technology now-a-days we use maximum of our data transfer through wireless like WiFi, Bluetooth, WI-Max,

145 International Journal for Modern Trends in Science and Technology 
etc. This project is designed as a plant monitoring system based on IOT.

In this project we use different modules such as IOT, arduino as controller, Temperature sensor, Moisture sensor, Humidity sensorl. This project uses sensors such as a humidity sensor is also given to know about the atmospheric humidity of that place. By having knowledge of all these one can take action accordingly. Moisture sensor sense the soil is dry or wet. If soil is dry automatically water pump will get ON. the sensor values are given to ADC to get processed by arduino controller. The temperature sensor LM35 senses the temperature and converts it into an electrical (analog) signal, which is applied to the micro controller through ADC. The analog signal is converted into digital format by the analog-to-digital converter (ADC).If temp increases more than set threshold value. Automatically fan will be ON.In this project we are using ARM7, dry/wet sensor, humidity sensor and Temperature sensor. The condition of soil and the temperature maintained are being displayed on LCD and the same values are updated in the internet through IOT module interfaced to the controller. and whenever smoke sensor is detected buzzer will be ON.

The LM35 series are precision integrated-circuit temperature sensors, whose output voltage is linearly proportional to the Celsius (Centigrade) temperature. The LM35 thus has an advantage over linear temperature sensors calibrated in ${ }^{\circ}$ Kelvin, as the user is not required to subtract a large constant voltage from its output to obtain convenient Soil moisture sensors typically refer to sensors that estimate volumetric water content. Another class of sensors measure another property of moisture in soils called water potential; these sensors are usually referred to as soil water potential sensors and include densitometers and gypsum blocks.

\section{RESULT \& DISCUSSION}

The performance of the system can be further improved in terms of the operating speed, memory capacity, and instruction cycle period of the microcontroller by using other high end controllers. The number of channels can be increased to interface more number of sensors which is possible by using advanced versions of controllers.

The system can be modified with the use of a data logger and a graphical LCD panel showing the measured sensor data over a period of time. A speaking voice alarm could be used. The device can be made to perform better by providing the power supply with the help of renewable source.Time bound administration of fertilizers, insecticides and pesticides can be introduced

\section{CONCLUSION}

This proposed work is made to help the ranchers and make their reap affordable by aiding them in security reason voyaging side, school and for each body and so forth By this work, the wastage of water and the utilization of force by engine can be diminished so they are rationed for the future use. This framework gives total observing activity of sensors in fields that is exceptionally simple to control the field. It additionally give enormous security to the plants.

\section{REFERENCES}

[1] Marwa Mekki2 ,Osman Abdallah1, Magdi B. M. Amin2, Moez Eltayeb1, Tafaoul Abdalfatah2, Amin Babiker3, "Greenhouse monitoring and control system based on wireless sensor networks "IEEE Trans. Syst ,Man,Cybern.,Appl.Rev.,vol.37,no.3,pp.311-314,May 2007

[2] Arul Jai Singh.S1, Raviram.P2, ShanthoshKumar.K3, "Embedded Based Green House Monitoring System Using PIC Microcontroller", IEEE Trans. Syst, Man, Cybern . A ,Systems and Humans, vol. 41, no. 6, pp.1064-1076, November 2011

[3] K.Lokesh Krishna ,J.Madhuri and Dr.K.Anuradha, "A ZigBee based Energy Efficient Environmental Monitoring Alerting and Controlling System", IEEE Trans.g, vol.3, no.1, pp.186- 190,2009

[4] Shiraz Pasha B.R., Dr. B Yogesha, "Microcontroller Based Automated Irrigation System", The International Journal Of Engineering And Science (IJES), Volume3, Issue 7, pp 06-09, June2014.

[5] Venkata Naga RohitGunturi, "Micro Controller Based AutomaticPlant Irrigation System", International Journal of Advancements inResearch \& Technology, Volume 2, Issue4, April-2013.

[6] Mahir Dursun and Semih Ozden, "A wireless application of dripirrigation automation supported by soil moisture sensors", ScientificResearch and Essays, Volume 6(7), pp. 1573-1582, 4 April, 2011.

[7] S. Harishankar, R. Sathish Kumar, Sudharsan K.P, U. Vignesh andT.Viveknath, "Solar Powered Smart Irrigation System", Advance inElectronic and Electric Engineering, Volume 4, Number 4 (2014),

[8] Pavithra D.S, M. S .Srinath, "GSM based Automatic IrrigationControl System for Efficient Use of Resources and Crop Planning byUsing an Android Mobile", IOSR Journal of Mechanical and CivilEngineering (IOSR-JMCE) Vol 11, Issue I, Jul-Aug 2014, pp 49-55.

[9] LaxmiShabadi, NandiniPatil, Nikita. M, Shruti. J, Smitha. P \& Swati.C, "Irrigation Control System Using Android and GSM for Efficient Use of Water and Power",International Journal of AdvancedResearch in Computer Science and Software Engineering, Volume4, Issue 7, July 2014 